\title{
Infliximab use in the Netherlands: Uptake and characteristics of originator and biosimilars over time
}

\author{
Jetty Overbeek ${ }^{1}$, Josephina Kuiper ${ }^{1}$, Marina Bakker ${ }^{1}$, Bart van den Bemt ${ }^{2}$, and Ron \\ Herings ${ }^{1}$
}

\author{
${ }^{1}$ PHARMO Institute for Drug Outcomes Research \\ ${ }^{2}$ Sint Maartenskliniek
}

March 4, 2021

\begin{abstract}
Aims: The objective of this retrospective cohort study was to provide an overview of the utilization of originator and biosimilar infliximab in the Netherlands. Methods: All infliximab dispensings were selected from the PHARMO In-patient Pharmacy Database from 2002-2018. Descriptive analyses were performed in order to characterise initiators and to describe switching patterns over time. Results: Overall, 3,840 patients with 61,274 infliximab dispensings were identified. 2,496 patients initiated an originator infliximab and 777 patients initiated a biosimilar infliximab. Overall, $57 \%$ of the patients was female and mean age was 43.2 years. Both originators and biosimilars were mostly prescribed by gastroenterologists, followed by internists and rheumatologists. After market authorization of the first biosimilar the proportion of new patients initiating the biosimilar increased from $39 \%$ in 2015 to $91 \%$ in 2018 . Out of 704 patients eligible for switching $34 \%$ switched. Among switchers, the proportion of females was $60 \%$ and mean age at index was 45.1 years. Among non-switchers, $55 \%$ was female and mean age was 39.8 years. The median time to switch was 1.7 years and switchers were most frequently initiated on infliximab by a rheumatologist (42\%), while non-switchers were most frequently initiated by a gastroenterologist (42\%). Conclusions: The results of this large population-based cohort show an increase in biosimilar initiation in daily clinical practice. The number of switchers remains relatively low as non-medical switch is not encouraged in the Netherlands.
\end{abstract}

\section{Hosted file}

Manuscript .pdf available at https ://authorea.com/users/399423/articles/511960-infliximab-usein-the-netherlands-uptake-and-characteristics-of-originator-and-biosimilars-over-time 

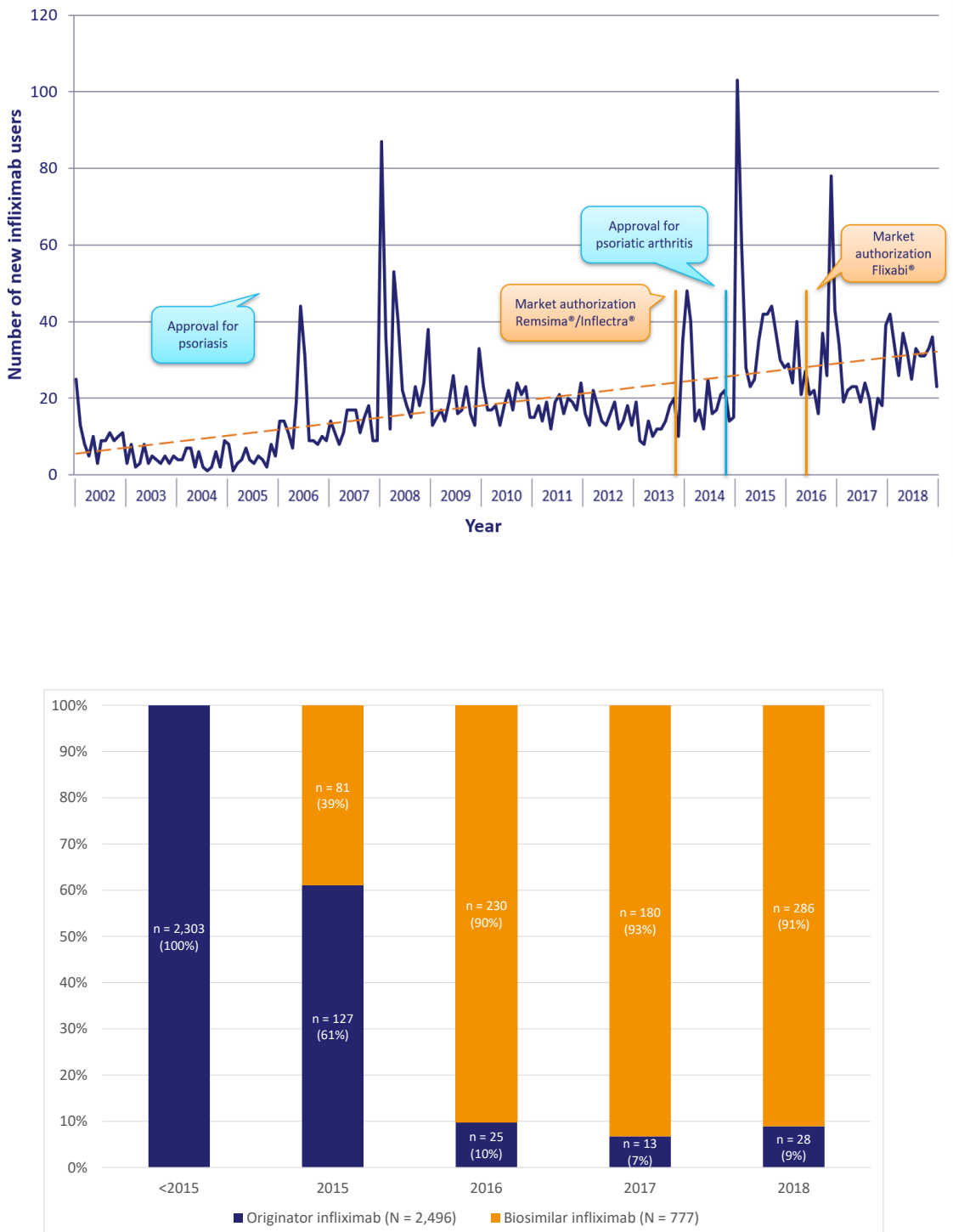